Сороко Григорий Янович

канд. экон. наук, ФГБОУ ВО «Государственный университет управления», г. Москва, Российская Федерация ORCID: 0000-0003-2405-2377 e-mail:gs150355@mail.ru

Коготкова Ирина Захаровна канд. экон. наук, ФГБОУ ВО «Государственный университет управления», г. Москва, Российская Федерация ORCID: 0000-0002-5617-4857 e-mail:izk2005@mail.ru

\section{Soroko Grigory}

Candidate of Economic Sciences, State University of Management, Moscow, Russia

ORCID: 0000-0003-2405-2377

e-mail: gs150355@mail.ru

Kogotkova Irina

Candidate of Economic Sciences, State University of Management, Moscow, Russia

ORCID: 0000-0002-5617-4857

e-mail: izk2005@mail.ru

\section{РАЗВИТИЕ ТЕОРИИ И ПРАКТИКИ ПРОЕКТНОГО УПРАВЛЕНИЯ: РОЛЬ НАУЧНОЙ ШКОЛЫ ГОСУДАРСТВЕННОГО УНИВЕРСИТЕТА УПРАВЛЕНИЯ (ЧАСТЬ 2)}

\begin{abstract}
Аннотация. Данная статья является продолжением публикации результатов исследования эволюции проектного управления как особого вида управленческой деятельности. Выделены основные события из истории формирования и развития теории и практики проектного управления как результата научного поиска ученых ФГБОУ ВО «Государственный университет управления». История развития и современное состояние теории проектного управления в ГУУ связаны с актуальными потребностями управленческой практики как на протяжении XX в., так и в настоящее время, поскольку совершенствование механизма проектного управления является одной из стратегий развития экономики страны.
\end{abstract}

Ключевые слова: управление, проект, проектная деятельность, управление проектом, Государственный университет управления.

Цитирование: Сороко Г.Я., Коготкова И.З. Развитие теории и практики проектного управления: роль научной школы государственного университета управления (часть 2)//Вестник университета. 2019. № 9. С 91-97.

\section{THE DEVELOPMENT OF THE THEORY AND PRACTICE OF PROJECT MANAGEMENT: THE ROLE OF THE SCIENTIFIC SCHOOL OF THE STATE UNIVERSITY OF MANAGEMENT (PART 2)}

\begin{abstract}
This article is a continuation of the publication of the results of the study of the evolution of project management as a special type of management activity. The main events from the history of formation and development of the theory and practice of project management as a result of scientific research of scientists of the State University of Management have been highlighed. The history of development and the current state of the theory of project management in the State University of Management are associated with the actual needs of management practice both during the twentieth century and now, because the improvement of the mechanism of project management is one of the strategies for the development of the country's economy.
\end{abstract}

Keywords: management, project, project activity, project management, State University of Management.

For citation: Soroko G.Ya., Kogotkova I.Z. The development of the theory and practice of project management: the role of the scientific school of the state university of management (part 2) (2019) Vestnik universiteta, I. 9, pp. 91-97. doi: 10.26425/1816-4277-2019-9-91-97

В опубликованной ранее части 1 одноименной статьи были рассмотрены тенденции развития теории и практики проектного управления, в том числе научной школы управления проектом ФГБОУ ВО «Государственный университет управления» (далее - ГУУ), до 1970-х гг. [3].

Становление и совершенствование методов и инструментов проектного управления было неразрывно связано с трансформацией электронно-вычислительных систем и программного обеспечения.

Во второй половине 1970-х гг. на западе стали выпускать модели мини-ЭВМ, для которых были разработаны первые диалоговые системы управления проектами, ориентированные на конечных пользователей, чья профессиональная деятельность была связана с планированием и реализацией крупных инженерных проектов.

В 1977 г. был выпущен первый вариант подобной автоматизированной системы управления от компании Oracle, которая в настоящее время выпускает линейку программ по управлению проектами Primavera.

(С) Сороко Г.Я., Коготкова И.З., 2019. Статья доступна по лицензии Creative Commons «Attribution» («Атрибуция») 4.0. всемирная (http://creativecommons.org/licenses/by/4.0/).

The Author(s), 2019. This is an open access article under the CC BY 4.0 license (http://creativecommons.org/licenses/by/4.0/).

(c) (i) 
Тогда же, в 1977 г., появилась профессиональная автоматизированная система управления строительством Artemis, которая очень быстро получила широкое распространение.

Говоря о факторах, повлиявших на развитие проектного управления, нельзя не сказать о появлении в середине 1970-х гг. персональных компьютеров (далее - ПК), определивших революционные изменения во всех областях информационной деятельности человека, и, конечно же, в сфере деятельности, которую мы называем сегодня проектным управлением.

Как уже упоминалось, в СССР для обобщения передового опыта автоматизации процессов управления строительством в 1972 г. был создан Центральный научно-исследовательский и проектно-экспериментальный институт автоматизированных систем в строительстве (далее - ЦНИПИАСС) [3]. Его научная тематика касалась самых разных аспектов автоматизации управления в строительстве, а не только автоматизации процессов сетевого планирования и управления (далее - СПУ).

Дело в том, что строительные организации реализовывали параллельно несколько проектов, и на первый план выходили задачи оптимального календарного планирования работ по всем проектам. Если использовать современную терминологию, это были задачи мультипроектного управления. Автоматизированные системы управления строительными организациями должны были обеспечивать эффективное решение этих задач.

Если проанализировать публикации 1970-х гг., то можно заметить, что количество работ по сетевому планированию и управлению значительно снизилось. Большинство публикаций посвящалось комплексному рассмотрению вопросов управления строительством, при котором методы СПУ позиционировались как составная часть общей системы управления строительной организацией, включающей в свой состав и множество других подсистем.

Но работы по автоматизации управления крупными строительными объектами на базе методов СПУ и отечественных ЭВМ продолжались. В качестве примера системы, основанной на использовании сетевой модели строительства, можно привести автоматизированную систему информационного обеспечения руководства (далее - АСИОР), разработанную под началом В. М. Розина в АО «Институт «Оргэнергострой». Эта система использовалась на строительстве Камского автомобильного завода и ряда других важнейших народнохозяйственных объектов.

В середине 1970-х гг. Московский ордена Трудового Красного Знамени инженерно-экономический институт имени Серго Орджоникидзе, готовивший кадры для базовых отраслей экономики, был переименован в Московский ордена Трудового Красного Знамени институт управления имени Серго Орджоникидзе (далее - МИУ) первую отечественную школу научного менеджмента. На каждом факультете помимо кафедр технологии, экономики и организации производства в отрасли создавались отраслевые кафедры организации управления.

Ректор МИУ поручил создание кафедры Организации управления в строительстве М. Л. Разу. Предполагалось, что для заведования кафедрой должен быть приглашен известный в отрасли специалист. В 1976 г. заведующим кафедрой Организации управления в строительстве стал О. А. Овсянников, вернувшийся из ЦНИПИАСС, М. Л. Разу стал выполнять функции заместителя заведующего кафедрой [3].

В конце 1970-х гг. в отечественные организации, осуществляющие строительство за рубежом, стали поступать первые экземпляры диалоговых компьютеров, что позволило начать разработку эффективных систем управления строительством. Одной из таких разработок стала система управления строительством крупного промышленного объекта в одной из африканских стран, реализованная на мини-ЭBM REALITE, работающей с системой Pick. В этом проекте участвовали и специалисты научно-вычислительного центра Московского ордена Трудового Красного Знамени института управления имени Серго Орджоникидзе (далее - НВЦ МИУ).

В период с 1978 по 1987 г. учеными кафедры было опубликовано множество работ по самым актуальным вопросам организации управления в строительстве. Тематика работы кафедры касалась вопросов бизнес-моделирования и проектирования процессов управления строительными организациями, автоматизацией процессов управления строительством и организационного проектирования, разработки для строительной отрасли комплексных целевых программ, игровому моделированию процессов управления строительством и пр. [2].

А обучение студентов методам СПУ осуществлялось на кафедре Планирования, организации и АСУ в строительстве. На ней же преподавался курс моделирования и автоматизации управления в строительстве, который вел пришедший на кафедру в конце 1960-х гг. О. В. Михненков, впоследствии возглавивший кафедру Организации управления в строительстве. 
Сетевой график представляет собой модель строительного производства, и как показали многочисленные исследования, его использование для отображения процессов управления в организациях не представляется целесообразным. Именно поэтому для отображения управленческих процессов стали использовать сетевые матрицы, разработанные на кафедре Теории управления МИУ.

Разработки, связанные с автоматизацией управления строительными организациями в ЦНИПИАСС, позволили создать удобную информационно-технологическую модель процессов управления, так называемые логико-информационные схемы (далее - ЛИС). Кафедра Организации управления в строительстве использовала ЛИС, сетевые и функциональные матрицы в качестве основных моделей процессов управления [4].

За несколько лет силами преподавателей кафедры, аспирантами и сотрудниками НВЦ МИУ было реализовано множество проектов по разработке и внедрению в строительных организациях разного уровня (от строительных управлений до подотдела строительства Госплана СССР) комплексной системы регламентного управления, базирующееся на использовании перечисленного комплекса моделей. Данная система предусматривала регламентацию как функциональных, так и целевых процессов.

Говоря о развитии компьютерных средств 1970-х гг, необходимо отметить, что в это время в качестве основной ЭВМ в НВЦ МИУ использовали машину «Минск-32». Но в конце 1970-х гг,, благодаря тому, что НВЦ МИУ выполнял хоздоговорные работы по заказам внешнеторговых объединений Министерства внешней торговли и Государственного комитета по внешнеэкономическим связям, в МИУ была установлена мини-ЭВM REALITE-2000, и специалисты НВЦ МИУ получили возможность работать с самой передовой техникой того времени.

Сотрудник НВЦ МИУ Л. В. Попов стал одним из ведущих в мире специалистов по системе Pick. В 1990-е гг. после закрытия НВЦ МИУ он был приглашен в качестве главного консультанта открытой в Москве лаборатории компании PickSystems.

Следует отметить, что ведущие научные организации СССР, такие как Институт проблем управления и отделение «Информатики» Академии наук получили доступ к технике данного класса на десятилетие позже.

В 1980-е гг. получили дальнейшее развитие методы создания больших и сложных систем, в которых строительные проекты входили как составные элементы. В западном менеджменте к этому времени все большее место занимает стратегическое планирование, развивается теория реализации инновационных проектов.

В начале 1980-х гг. начался массовый выпуск персональных компьютеров (далее - ПК). Их доступность (по стоимости, габаритам и пр.) для любых категорий пользователей привела к появлению широкого спектра компьютерных программ, которые позволяли осуществлять планирование и составление графиков работы для любых сфер деятельности и в оперативном режиме отслеживать, как эти графики выполняются. С появлением таких программ стало возможно легко вносить в исходные планы любые изменения и визуализировать процессы фактического выполнения задуманных работ.

Быстрыми темпами расширялась производительность автоматизированных систем управления проектами. Возможность оперативной обработки больших объемов информации, позволила приступить к практическому решению задач проектного управления в разных сферах деятельности.

Развитие методов проектного управления на базе ПК привело к их большой популяризации и широкому использованию. К этим методам стали стали обращаться не только крупные, но и средние и мелкие фирмы. Очень быстро эти инструменты пользователи стали активно применять при решении не только профессиональных, но и любых других задач.

В это время продолжаются работы по выявлению и обобщению опыта управления проектами. В 1987 г. в США опубликована работа сотрудников Американского института проектного управления (англ. Project Management Institute; PMI) «Свод знаний по проектному управлению» (англ. Project Management Body of Knowledge; PMBoK). В ней сделана первая попытка определения места, роли и содержания методов и средств проектного управления.

В 1980-е г. в СССР активно осуществляются работы по совершенствованию методов программно-целевого планирования и управления. В стране реализуется множество комплексных целевых программ.

Однако действующие в стране экономические механизмы не способствовали практическому внедрению методов проектного управления.

Разработчик отечественной автоматизированной системы управления проектами SpiderProject, В. И. Либерзон, в советское время сотрудник Центрального научно-исследовательского института комплексной автоматизации при Министерстве приборостроения, оценивая этот период, отмечает, что не было заинтересованности 
в оптимизации плановых сроков проектов, поскольку следующий план мог стать более жестким. Однако были довольно интересные работы в области сетевого планирования с высоким уровнем теоретической проработки [6].

В это время появились отечественные мини-ЭВМ, работающие в диалоговом режиме. Для этого периода характерны процессы переноса задач, решаемых ранее на больших машинах, на мини-ЭВМ. В числе этих задач были и задачи СПУ.

На кафедре Организации управления в строительстве МИУ продолжались работы по развитию методологии создания комплексных систем регламентного управления организациями и регламентации управления целевыми комплексными программами.

Защищались диссертации по управлению процессами реализации инвестиционно-строительных проектов, по мультипроектному управлению строительством крупных промышленных комплексов, по регламентации управления целевыми комплексными программами развития главных управлений строительных министерств.

В 1983 г. на кафедру Организации управления в строительстве пришел профессор А. А. Венгеров. Благодаря его усилиям, сотрудники кафедры получили в свое распоряжение микро ЭВМ ДВК-2, которую можно было использовать в персональном режиме на индивидуальном рабочем месте.

На этой ЭВМ силами студентов, аспирантов, сотрудников кафедры и НВЦ в 1986 г. на основе документов, сформированных в автоматизированной системе Artemis, в рамках договора МИУ с Государственным комитетом по внешнеэкономическим связям, была разработана оригинальная отечественная система управления строительным проектом. Она успешно прошла промышленную эксплуатацию при управлении строительством атомной станции в Финляндии. К сожалению, после Чернобыльской катастрофы эти работы были приостановлены.

Один из участников этого проекта, аспирант кафедры В. В. Булгаков, вскоре защитил диссертацию по управлению внедрением автоматизированных информационных технологий управления строительством. В ней, по существу, предлагалась методология гибкого управления ИТ-проектами, столь популярная сегодня.

В дальнейшем под руководством А. А. Венгерова силами созданного им студенческого научно-производственного объединения (далее - СУНПО) были выполнены разработки автоматизированных рабочих мест специалистов по оперативному управлению строительством на важнейших стройках Москвы, осуществляемых Главмоспромстроем. В состав этих систем входил и блок сетевого планирования и управления проектами.

Эти разработки легли в основу научных исследований кафедры по организации штабов управления строительством сложных объектов (прообраз проектного офиса).

К числу интересных работ того периода следует отнести также проект по интеграции сетевой модели строительного производства с информационно-технологическими моделями процессов управления этим производством.

Следует особо отметить, что уже в начале 1980-х гг. студенты строительного факультета МИУ имели возможность работы на ЭBM REALITE. Так в 1982 г. студентами кафедры Организации управления в строительстве была разработана деловая игра «Строй-5», имитирующая процессы календарного планирования и управления строительством [1].

К числу важных направлений деятельности кафедры Организации управления в строительстве в этот период следует отнести и создание первого в стране Центра деловых игр (научный руководитель М. Л. Разу). В Центре был сформирован уникальный банк деловых игр вузов СССР, в котором было множество игр, имитирующих процессы управления строительными проектами.

Таким образом, можно сделать вывод о том, что кафедра Организации управления в строительстве ГУУ еще в 1980-е г. активно развивала процессный подход к управлению строительством. Причем этот подход использовался применительно как к функциональному, так и целевому управлению.

Во второй половине 1980-х гг. усилиями сотрудников НВЦ удалось получить и начать освоение интегрированного программного пакета REVELAITION, созданного в 1986 г. бывшими инженерами компании PickSystems для работы на персональных ЭBM. Система REVELAITION была полностью совместима с системой Pick и позволяла использовать наработанные ранее программы. Использование интегрированного пакета REVELAITION позволило реализовать десятки проектов автоматизации рабочих мест специалистов строительства. Эти системы успешно поддерживались до середины 2000-х гг.

К началу 1990-х гг. проектное управление окончательно оформилось как отдельная сфера профессиональной деятельности. Были разработаны международные стандарты, включающие набор требований к управлению проектами, к обучению этому виду деятельности, тестированию и сертификации специалистов. 
В 1990-е гг. появилось множество компаний, в том числе и транснациональных, осуществляющих управление проектами в самых разных областях человеческой деятельности. Выпускник строительного факультета МИУ, успешно защитивший кандидатскую диссертацию в 1989 г. на кафедре Организации управления в строительстве, Ф. Мустафаев работал в 1990-е гг. в крупной голландской компании по управлению проектами. По его оценкам, предлагаемый рынком стандартный инструментарий по управлению проектами был не очень удобен в практической работе. В связи с чем, он сформировал собственную графическую модель для управления реализацией проектов, представлявшую собой комбинацию календарного графика и функциональной матрицы, разработанной в МИУ. Руководство компании оценило достоинства предложенной модели и ее стали использовать в качестве корпоративного стандарта.

Быстрое развитие вычислительной техники, массовый выпуск ПК, которые по своим характеристикам стали превосходить технику предшествующего поколения, переход на графические интерфейсы способствовал и ускоренному развитию, и широкому распространению автоматизированных систем управления проектами. В качестве признака осознания важности этого направления деятельности, можно рассматривать включение системы управления проектами в офисный пакет известного компьютерного гиганта.

Произошедшие в стране экономические преобразования 1990-х гг. имели множество негативных последствий. Были разрушены многие отечественные научные школы, перестали функционировать важные научные центры. Эти негативные явления коснулись и вузов. Прекратил свое существование НВЦ МИУ.

В то же время эти преобразования имели и положительные моменты.

Прежде всего, следует отметить, что отечественные специалисты получили доступ к самой современной компьютерной технике и программному обеспечению, что практически устранило наше отставание по этому направлению. Россия стала равноправным членом международного научного сотрудничества.

Активное развитие получили и международные ассоциации по управлению проектом, основной целью которых является обмен знаниями в данной предметной области.

25 октября 1990 г. учреждено российское некоммерческое партнерство «Ассоциация управления проектами «СОВНЕТ». Ее первым президентом стал В. И. Воропаев, один из ведущих советских специалистов в области сетевого планирования и управления, бывший сотрудник ЦНИИПИАС, уже упомянутый в нашей статье ранее.

Учредителями СОВНЕТ стали: Центральный научно-исследовательский институт экономики и управления в строительстве (далее - ЦНИИЭУС); Государственный университет управления (далее - ГУУ); Московский государственный строительный университет (далее - МГСУ); Институт проблем управления Российской академии наук (далее - ИПУ) и др.

Следует признать, что в 1990-е гг. преобладало распространение и продвижение зарубежных подходов и тенденций в отечественную практику проектного управления [4].

Но имелись и обратные примеры. Здесь в первую очередь следует сказать об отечественной автоматизированной системе проектного управления SpiderProject, мощном и удобном средстве управления проектами, достойно конкурирующем с ведущими иностранными аналогами. Первая версия системы была выпущена в 1992 г. и уже в 1993 г. демонстрировалась на выставках в России, а также в Лейпциге и Мюнхене. В настоящее время SpiderProject используется в десятках стран мира и в большинстве крупных программ России. Среди тысяч пользователей системы представители всех отраслей экономики [4].

Все возрастающая роль и значение проектного управления в современном менеджменте обуславливала необходимость во всемерном развитии теории и практики проектного управления.

Специалисты строительного факультета МИУ (с 1991 г. ГАУ) обладали большим опытом и знаниями в области управления строительными проектами и целевыми программами. В связи с этим в 1996 г. руководством академии было принято решения о создании на строительном факультете (институте) первой в стране кафедры Управления проектом. Ее возглавил один из ведущих специалистов в области организационного управления профессор М. Л. Разу.

Преподавательский состав был сформирован из сотрудников кафедры Организации управления в строительстве А. В. Гусевой, Т. М. Бронниковой и Е. А. Выходцевой. Пришел на кафедру и В. И. Воропаев.

Ими была выполнена огромная работа по созданию учебно-методического обеспечения подготовки специалистов по проектному управлению. Один из ведущих российских специалистов в области проектного управления профессор С. А. Титов был среди студентов первого выпуска кафедры Управления проектом. 
В 1990-е гг. коллективом университета под руководством ректора А. Г. Поршнева совместно с Национальным центром подготовки кадров был разработан и реализован масштабный проект по созданию модульного учебника по менеджменту. В 1998 г. был опубликован модуль по управлению проектами, подготовленный кафедрой М. Л. Разу [5].

В первое десятилетие нового века развитие систем управления проектами осуществлялось в направлении, обусловленном новыми возможностями вычислительной техники. Этот период можно характеризовать как переход от локальных систем автоматизации к корпоративным сетевым. Совершенствование сетевых технологий позволяло создавать многопользовательские системы управления проектами. Такие системы существовали и ранее. Уже первые версии системы Artemis, реализованные на мини-ЭВМ, обеспечивали многопользовательский режим. Однако достаточно высокая стоимость этих машин ограничивала их широкое распространение.

Функциональные и стоимостные характеристики персональных ЭВМ позволяли создавать сетевые варианты систем управления проектами нового поколения. Массовое использование систем данного типа способствовало их быстрому совершенствованию. Появились линейки программных продуктов по управлению проектами различных производителей, предлагающие пакеты, серьезно различающиеся по функциональности и стоимости.

Как уже было сказано, российские специалисты по управлению проектами имели в своем распоряжении те же системы автоматизации, которые использовались во всем мире.

В этот период продолжается широкое распространение методологии проектного управления в различные сферы деятельности. Преподавание проектного управления осуществляется уже во множестве учебных заведений Российской Федерации.

В 2000-е гг. увеличивается количество студентов и аспирантов, обучающихся на кафедре управления проектом. Защищено множество диссертаций, посвященных приложению методов проектного управления к различным сферам деятельности.

В 2008 г. вышло первое издание фундаментального учебника по управлению проектами, в котором отражен многолетний опыт ученых нашего университета в этой предметной области. Это учебник многократно переиздается до настоящего времени [4].

Во втором десятилетии развитие систем управления проектом обусловливается развитием глобальной сети, стандартным требованием к системам автоматизации становится возможность доступа пользователей через сеть «Интернет», использование web-технологий. Практически все производители автоматизированных систем управления проектами в настоящее время обеспечивают эти возможности.

В последнее время наметилась устойчивая тенденция интеграции систем автоматизации проектного управления с автоматизированными информационными системами организаций (далее - АИСО).

Дело в том, что значительная часть задач, решаемых АИСО, имеет достаточно четко выраженный проектный характер. Например, задачи подсистем стратегического планирования и инновационного развития. В связи с этим АИСО включают в свой состав специализированные блоки по управлению проектами.

Кроме того, некоторые программные системы, изначально предназначенные для иных целей, например, системы по формированию проектно-сметной документации, стали дополняться функциональностью по управлению проектами. Это вполне логично, так как сметные программы формируют структуру будущего объекта и очень удобно воспользоваться этой структурой для построения структуры работ и их расписаний.

В тоже время наблюдается и обратный процесс. Ведущие разработчики автоматизированных систем проектного управления расширяют их функциональность и закладывают возможности, направленные на интеграцию систем проектного управления в корпоративные информационные системы.

В современном бизнесе при постоянно растущей сложности проектов, когда перед организациями ставятся задачи достижения намеченных целей в сжатые сроки и с минимальными затратами, невозможно рассматривать методологию управления проектами в отрыве от других информационных технологий.

Сформировалась потребность создания корпоративных систем управления проектами, обеспечивающих управление по проектам со сквозным контролем всех проектов, работ, а также трудовых, материально-технических и финансовых ресурсов в рамках одной или группы компаний (финансового или производственного холдинга).

Современные системы позволяют осуществлять управление уже не отдельными проектами, а всей совокупностью проектов организации - как к внутренними, так и к внешними. Здесь напрашивается аналогия с процессами, происходящими в 1970-е гг., когда от систем планирования и управления отдельными строительными 
проектами переходили к системам управления множеством проектов. В настоящее время по существу реализуются аналогичные процессы, но на новом технологическом уровне.

С 2011 г. после кончины М. Л. Разу кафедру Управления проектом возглавляет А. М. Лялин, защитивший на кафедре докторскую диссертацию.

В этот период была проведена большая работа по обновлению учебно-методического обеспечения, связанного с переходом на новые образовательные стандарты и двухуровневую систему подготовки. Дисциплина «Управление проектом» была включена в базовый учебный план подготовки бакалавров по всем образовательным программам направления «Менеджмент».

В настоящее время большинство сотрудников кафедры являются непосредственными учениками М. Л. Разу (М. Н. Гусева, И. С. Брикошина, Н. Г. Малышкин, Т. Ф. Чернова, С. А. Никитин, Е. А. Халимон, Е. В. Никитина, Н. В. Титова и авторы этой статьи) продолжающими и развивающими его научную школу.

Большие перспективы перед кафедрой Управления проектом открываются в связи с новой стратегией ГУУ, направленной на развитие цифровизации и отраслевого менеджмента.

Начавшееся в ГУУ техническое переоснащение позволит получить доступ к самому современному программному обеспечению по управлению проектами. Это особенно значимо на современном этапе развития теории и практики проектного управления в ГУУ, так как ученые кафедры ведут разработки оригинальных систем по гибкому управлению проектами - современному тренду в данной области, необходимому для эффективной реализации цифровых проектов.

Кроме того, хотелось бы возродить традиции университета, который, как видно из приведенных здесь материалов, всегда находился в авангарде развития информационных технологий в области проектного управления.

\section{Библиографический список}

1. Разу, М. Л. Деловые управленческие игры по курсу «Организация управления в строительстве» / М. Л. Разу, И. В. Беляев. - М.: МИУ, 1983 г. -67 с.

2. Сороко, Г. Я. и др. Теоретические и методические основы моделирования и автоматизации процессов управления в строительстве: учебное пособие / Г. Я. Сороко, Н. С. Куприянов, О. В. Михненков. - М.: ГУУ, 2012. - 88 с.

3. Сороко, Г. Я. Развитие теории и практики проектного управления: роль научной школы Государственного университета управления (часть 1) / Г. Я. Сороко, И. 3. Коготкова//Вестник университета. - 2019. - № 8. - С. 111-117.

4. Управление проектом. Основы проектного управления: учебник / коллектив авторов; под ред. проф. М. Л. Разу. 3-е изд., перераб. и доп. - М.: КНОРУС, 2010. - 760 с.

5. Управление программами и проектами: 17-ти модульная программа для менеджеров «Управление развитием организации». Модуль 8 / под ред. М.Л. Разу. - М.: ИНФРА-М, 1999. - 364 с.

6. Проект Spider project [Электронный ресурс]. - Режим доступа: http://erazvitie.org/article/proekt_spider_project/ (дата обращения: 22.07.2019).

\section{References}

1. Razu M. L., Beliaev I. V., Delovye upravlencheskie igry po kursu "Organizatsia upravlenia v stroitel'stve" [The management business game on the course "Organization management in construction"]. M.: MIU, 1983. 67 p.

2. Soroko G. Y., Kuprianov N. S., Mikhnenkov O. V. Teoreticheskie i metodicheskie osnovy modelirovania i avtomatizatsii protsessov upravlenia v stroitel'stve: uchebnoe posobie [Theoretical and methodical bases of modeling and automation of control processes in construction: textbook]. M.: GUU, 2012. 88 p.

3. Soroko G. Y, Kogotkova I. Z. Razvitie teorii i praktiki proektnogo upravlenia: rol' nauchnoi shkoly Gosudarstvennogo universiteta upravlenia (chast'1) [Development of theory and practice of project management: the role of the scientific school of the State University of Management (part 1)]. Vestnik universiteta, 2019, I. 8, pp. 111-117.

4. Upravlenie proektom. Osnovy proektnogo upravleniya: uchebnik [Managing project. Basics of project management]; kollektiv avtorov; pod red. prof. M. L. Razu; 3-e izd., pererab. i dop. M.: KNORUS, 2010. 760 p.

5. Upravlenie proektami i programmami: 17-ti modul'naya programma dlya menedzherov "Upravlenie razvitiem organizatsii". Modul' 8. [Program and project management: 17-modular program for managers "Management of organization development". Module 8]; pod red. prof. M. L. Razu. M.: INFRA-M, 1999. 364 p.

6. Proekt Spider project [Project Spider project]. Available at: http://erazvitie.org/article/proekt_spider_project/ (accessed 22.07.2019). 